\title{
Application of Computer Technology in Advanced Material Science and Processing
}

\author{
Yajuan Liu* \\ SoftSchool, East China JiaoTong University, Nanchang, P.R. China \\ Tel.: +86-791-7046184; Fax: +86-791-7046185 \\ liuyajuanlyj@tom.com
}

\begin{abstract}
Computer technology is an actual system model, which is largely unaffected by experimental conditions, time and space constraints, and is of great flexibility. Nowadays, computer technology has thoroughly penetrated in the various areas of material processing and research, which becomes one of the important frontiers in the field of material manufacturing industry. At the same time, material science and technology are also developing rapidly and constantly giving birth to the new industrial field, such as nanotechnology, optoelectronic, magnetic electronic technologies, which are inseparable of computer technology. Hence, in this article, the application of computer technology in advanced material science and processing, which includes material science database, computational material science, computer-aided design or processing etc are reviewed.
\end{abstract}

Keywords: Computer Technology, Material Processing, Material Science.

\section{Introduction}

With the continuously deepening research of material science, material science occupies an important position in the national economy; however, material science is still an immature interdisciplinary, which mainly depends on the facts and the experience of the current study. The systematic studies need a very long process[1]. Computer as a modern tool plays an increasingly significant role in various areas of the world, which has penetrated into many fields. With respect to the material science and engineering, the computer is also becoming a very important tool and becomes one of the reasons for the accumulation of the rapid development of material science. For example, computer technology has been widely used in the variety field of material forming technology, including application in liquid forming, plastic forming, polymer material forming, powder forming et al, which can basically provide a qualitative description toward to quantitative prediction for material processing[2-3]. Furthermore, computer application in material science is the trend of multi-scale simulation and integration[4-5]. In this

\footnotetext{
* Corresponding author.
} 
article, the application of computer technology in material science and processing including material science literature search practice, computational material science, computer-aided design and processing are mainly introduced.

\section{Computer Technology in Material Science Databases}

A reasonable choice of material, accurate design and scientific processing are directly impacting on product cost and quality, which even affect the social development and progress. In recent years, with computer technology development, particularly in the development of database technology, material science databases in scientific research has become increasingly emphasized and get more and more widely used. A sample material database was illustrated in Figure 1.

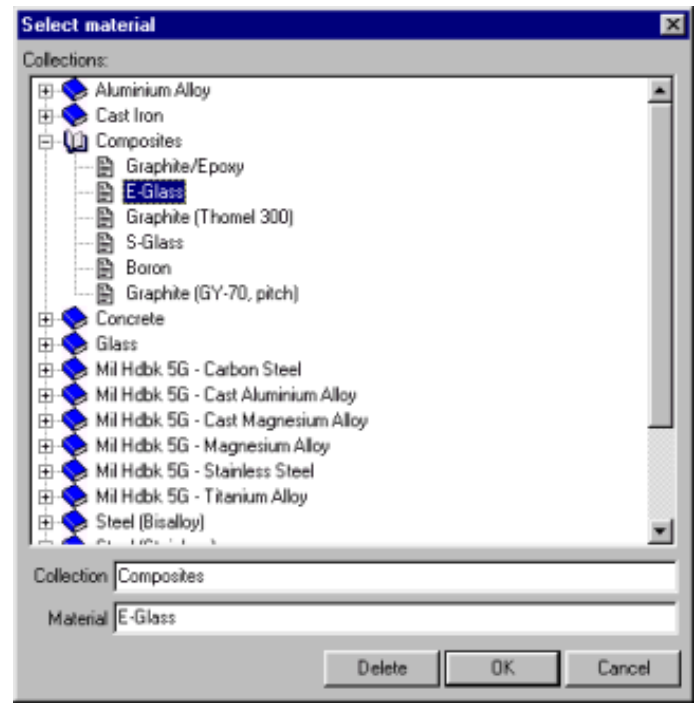

Fig. 1. A sample of material database

Material science database can be divided into the data type, numeric type as well as the map database. Otherwise, it is also divided into the online and offline database type. The literature database is of mainly online services, while numerical databases were more used in off-line. Moreover, according to the point view of material, it can be classified into metallic and nonmetallic material databases.

Public material databases have been constructed every year and the developed countries continue to make the information on this strategic. Numeric material database has been established in China since 1992 and has accumulated in recent years[6]. Though after several decades of development and accumulated, however, the following deficiencies still exist: (1) The lack of the data of mechanical properties. In the development of metallic material database, it focuses on the iron and steel materials, 
however, with respect to the light alloys such as aluminum, magnesium alloys, it was still lack of the mechanical properties' database.(2) The lack of the data of material processes performance. Cold and hot processing of material data is rarely found. (3) Although some scientific databases of materials have built at home and abroad, its research and development still lags far behind the actual rate of application requirements. Generally, network, standardization, intelligence and commercial trends will make the application material database, extended to broader areas of material research and development.

\section{Computational Material Science}

Computational material science (CMS) is a typical interdisciplinary of material science and computer science, which is the material scientific research about the "computer design" and "computer experiment" in material composition, structure, performance, service performance[7]. According to the literatures[8], CMS could be mainly included into two aspects: one is calculation and simulation, which is starting from the experimental data, through the establishment of mathematical models and numerical calculations to simulate the actual process; the other is the computer added material design, which is directly through the theoretical model to calculate, predict or design the new structure and properties of material. Therefore, CMS is a bridge to connect theory and experimental material.

It is well known that the material composition, structure, performance and service performance are the four elements of material research. The traditional research is based material experimental results in the laboratory, which is an experimental science. However, with the requirements of high material performance increasing, especially because the material sciences research object is constantly changing spatial scale into small, the micro-level studies do not reveal the nature of material properties, nano-structures and atoms scale and even electronic level become the studied content when the functional material are studied[9]. Therefore, material research is increasingly dependent on high-level testing technology, the research difficulty and costs are getting much higher.

In addition, the service performance is increasing attention in material research, which is to study the interaction of material and service environment and its impact on material performance. As the material was serviced in an increasingly complex environment, laboratory studies of service performance have become more and more difficult. In short, it was difficult that the new and modern material research and development relying solely on laboratory experiments to conduct material research. Computer simulation technology, however, according to the basic theory, from the inclusive concept of a virtual environment, micro-, meso-, macro-scale, multi-level research on the material in the computer, but also can simulate the ultra-high temperature, high pressure material under extreme environments such as service performance to simulate material properties under service conditions, failure 
mechanism, so as to realize the performance of material in service improvements and material design. Thus, in the field of modern material science, the computer "experiment" has the same important position in research methods.

It is necessary to point that CMS is closely related to computer development. In the past, even if the use of large computers is also very difficult to calculate a number of materials, such as material, quantum mechanic calculations, now it can complete this on PC. In addition, with the continuous progress of CMS and mature, material, computer simulation and design is no longer a hot research topic of just theoretical material physics and material scientists calculated, but also will become an important research tool of general-purpose material researchers.

\section{Computer Aided Design and Manufacture}

The initial processing of computer used for complex engineering analysis and calculation is followed by the development process in the modern industrial product design, such as the aircraft surface flow field calculation, the stress analysis of the complex structure[10]. The system can do a lot of complex calculations in a very short period of time, and it is possible for many programs for rapid analysis and evaluation to choose the best design.

Material processing CAD can be divided into casting CM, plastic forming CAD, welding forming $\mathrm{CAD}$, injection molding $\mathrm{CAD}$, as well as mold CAD[11]. The computer simulation of casting process was carried out earlier and the technically is more mature, which has been into the micro-macro simulation stage. From the early 90 's in 20 centuries, it has launched the computer simulation of micro-morphology, in which it can simulate the nucleation, growth the process of casting solidification process of forecasting[12-14]. After years of research and development, a large number of casting process simulation software has been the commercialization, which is shown in Table 1[15].

Table 1. Overview of main foreign casting special software

\begin{tabular}{lll}
\hline Software name & Developer & Function \\
\hline Mavls software & Alphacast software Ltd & $\begin{array}{l}\text { Predicted melt flow temperature, pressure, } \\
\text { velocity distribution, macro-and } \\
\text { micro-shrinkage, dendrite arm spacing, } \\
\text { steady-state temperature distribution }\end{array}$ \\
\hline Flow-3d & Flow science, Inc & $\begin{array}{l}\text { Automatically predicted solidification } \\
\text { shrinkage, binary segregation and tracking } \\
\text { of surface defects }\end{array}$ \\
\hline ProCast & UES software,Inc & $\begin{array}{l}\text { formation of micro-structure such as } \\
\text { porosity, pore aggregation }\end{array}$ \\
\hline Cast CAE4 & Finland & $\begin{array}{l}\text { Calculated solidification shrinkage, } \\
\text { formation of 3-D view }\end{array}$ \\
\hline
\end{tabular}




\section{Conclusion}

In summary, material science is a cross-emerging for the development of immature discipline. At present, its research is largely depended on the facts and the experience. The systematic studies need a very long process. The computer is becoming an extremely important tool, which is one of the important reasons for rapid development of material science. The use of computers for design of new material has gradually been recognized and used. However, this understanding and effort are still insufficient. Facing the future, computer simulation technology, material calculation and design will become an inevitable trend.

\section{References}

1. Flaszka, W.G., Paro, J.A., Kivivuori, S.O.J.: Computer-aided forging design using model material simulation. J. Mater. Process. Technol. 24, 403-409 (1990)

2. Joshi, K., Lauer, T.W.: Impact of information technology on users' work environment: A case of computer aided design (CAD) system implementation. Inf. Manage. 34, 349-360 (1998)

3. Sapuan, S.M.: A knowledge-based system for material selection in mechanical engineering design. Mater. Des. 22, 687-695 (2001)

4. Gates, T.S., Odegard, G.M., Frankland, S.J.V., Clancy, T.C.: Computational materials: Multi-scale modeling and simulation of nanostructured materials. Compos. Sci. Technol. 65, 2416-2434 (2005)

5. Hao, S., Liu, W.K., Moran, B., Vernerey, F., Gregory, B.O.: Multi-scale constitutive model and computational framework for the design of ultra-high strength, high toughness steels. Compos. Methods in Appl. Mech. Eng. 193, 1865-1908 (2004)

6. http: //www. csdb.cn/viewdb.j.sp?uri=cn.csdb.material

7. Sokrates, T.P.: Frontiers in computational materials science. Compos. Mater. Sci. 2, 149-155 (1994)

8. Richard, P.M.: Computational materials science -a personal perspective of an industrial scientist. Compos. Mater. Sci. 2, 161-167 (1994)

9. Hafner, J.: Atomic-scale computational materials science. Acta Mater. 48, 71-92 (2000)

10. Wan, H.: Application of computers in materials science. Sci. Technol. of Aotou Steel Corp. 31, 6-9 (2005)

11. Bata, G.L., Salloum, G.: Computer integrated material processing (CIMP) -A generic application of CAD/CAM technology. Mater. Des. 8, 220-228 (1987)

12. Jerald, R.B., Sanjay, J., John, W.D., Srinivas, P.: Application of computer-aided engineering techniques to tooling for castings. J. Manuf. Syst. 11, 215-223 (1992)

13. Im, Y.T.: A computer-aided-design system for forming processes. J. Mater. Process. Technol., 89-90, 1-7 (1999)

14. Karima, M., Richardson, J.: A knowledge-based systems framework for computer-aided technologies in metal forming. J. Mechan. Work. Techn. 15, 253-273 (1987)

15. Cao, H.J., Song, Y.P., Wang, W.Y.: The application and development of Computer Simulation of Casting Process. J. Henan Univ. Sci. and Techn.: Nat. Sci. 27, 5-8 (2006) 